POPE : A METHOD OF STUDYING POLYMORPHISM, ETC.

\title{
XLIII.-A Method of Studying Polymorphism, and on Polymorphism as the Cause of some Thermal Peculiarities of Chloral Hydrate.
}

By Iilliam Jackson Pope.

IN studying the thermochemical behaviour of chloral hydrate, Berthelot made the remarkable discovery that the latent beat of fusion of the freshly solidified substance is only about one-half of that of material solidified several days previously (Ann. chim. phiys., 1877, [v], 12, 536). This retention of part of the latent heat of fusion seems at first sight highly anomalous, and Berthelot considers (loc. cit., p. 565) that it may be explained by assuming that the substance remains soft and pasty for some time after solidification, and does not change sharply from the liquid to the solid state. Differences between the latent heat of fusion and of solidification may consequently be attributed either (1) to differences in plasticity, or (2) to differences in crystalline form; this distinction is one of great importance, and but little evidence supporting it has been advanced. I have, therefore, examined the case of chloral hydrate, in which Berthelot attributes the thermal peculiarities to the assumption of a plastic condition on solidification, in order to ascertain whether the distinction made by Berthelot is necessary; the results of the work now brought forward show that the distinction is unnecessary, at any rate in the case of chloral hydrate, the differences in plasticity being due merely to differences in crystalline form.

On melting a few grams of chloral hydrate in a test tube and pouring the liquid on to a slab, it solidifies to what is seen by macroscopic examination to be a felted aggregate of minute needles; the solid mass is somewhat pasty in character, and does not readily crumble between the fingers. Un preserving the mass in a stoppered bottle for some days, it becomes more macrocrystalline in character, and loses its felted appearance; it is then much more friable, and crumbles easily between the fingers. In order to obtain the chloral hydrate in a form suitable for crystallographic examination, a little is placed on a microscope slide under a cover-slip, and the slide gently warmed; as soon as fusion has occurred, the cover-slip is pressed down so as to spread the drop of liquid over its whole area and the slide is placed aside to cool. After a few minutes, solidification sets in at some particular point, and then crystallisation rapidly proceeds until the whole is solid. A very thin film of the crystalline substance is thus readily obtained free from air-bubbles, and in a form in which it can be exhaustively ex- 
amined in the polarising microscope. The film consists entirely of long, flattened needles, a great proportion of which do not illuminate on rotation in a parallel beam between crossed Nicols; these seem to be uniaxial, the optic axis emerging normally to the plate. Many of the needles, however, illuminate brilliantly between crossed Nicols and show straight extinction; the ends of these are cut off by two symmetrically placed faces. All these acicular crystals seem to be crystallographically similar, although some, probably owing to internal strain, are biaxial. On again examining the section after about 12 hours, a number of diamond-shaped plates are observed distributed about amongst the needles; these are monosymmetric, and show an optic axis emerging obliquely through the large, flat face which is in the plane of symmetry zone. The latter plane is the optic axial plane. As more time elapses, the number and size of these monosymmetric crystals increase, and the quantity of the needles decreases, until after six or seven days the whole preparation becomes converted into the monosymmetric form.

It is thus evident that crystalline chloral hydrate exists in at least two forms, namely, a $\beta$-modification, unstable at ordinary temperatures, and crystallising in uniaxial needles, and an $\alpha$-modification, stable at ordinary temperatures, and crystallising in monosymmetric plates. Further, the change of the $\beta$ - into the $a$-modification proceeds slowly, requiring at ordinary atmospheric temperatures several days for its completion.

As is well known, the conversion of one crystalline modification of a substance into another by a fall in temperature is accompanied by development of heat. It is, therefore, hardly to be doubted that the varying latent heat of fusion of chloral hydrate is due to the determinations being made with mixtures in various proportions of $\alpha$ - and $\beta$-chloral hydrate ; the $\beta$-modification necessarily has the smaller latent heat of fusion, and as, at ordinary temperatures, its quantity continously decreases, the apparent latent beat of fusion continuously increases as time goes on.

Since the $\beta$-modification is stable at the higher temperature, it might be expected to revert to the $\alpha$-modification more readily at low temperatures than at higher ones, and this tendency should make itself apparent by an increased speed of change. This was fully substantiated by experiment; on keeping a freshly solidified film of the $\beta$-variety at $-18^{\circ}$ for 2 hours, a great part of it became converted into the $\alpha$-modification; the same change would have required at least a day at the ordinary temperature. The increased speed of conversion at low temperatures is easily traced by comparing results obtained during the summer and winter months. Apart from this temperature influence, considerable differences are observed between various 
samples of chloral hydrate in the speed of conversion of the $\beta$-into the $a$-modification; these are probably due to the different degrees of impurity of the samples.*

Although it is readily ascertained by microscopic examination that chloral hydrate is dimorphous, yet the interconversion of the two modifications is of so interesting a nature that it was desirable to obtain a method by which the progress of the change of the $\beta$-into the $\alpha$-variety from day to day could be permanently recorded in a manner free from the personal bias inseparable from freehand drawings. This end was simply and satisfactorily accomplished by photographing the microscopic preparations between crossed Nicols. An optical bench was constructed by Messrs. Baird and Tatlock, on which are mounted, in the order named, an incandescent gas lamp, a projection lantern condenser, a polarising microscope with tube arranged horizontally, and, lastly, a quarter-plate camera without a lens; the lamp, condenser, and camera are so arranged as to be optically concentric with the microscope. An ocular may or may not be used in the microscope, but it is preferable to use ani ocular, as by so doing a 'flare-spot,' which made its appearance on the ground glass with several microscopes when no eyepiece was used, was eliminated. The crystal preparation to be photographed is placed on the microscope stage, and by simultaneously racking the camera back and the objective backwards and forwards, an image of the required size is focussed on the screen; the slide is then adjusted on the stage until the part to be photographed occupies the field of view. After finally focussing by aid of the fine adjusting screw of the microscope, the picture may be photographed. Using a 1-inch objective of N.A. $=0.25$, and a total magnifying power of about 60 diameters, the necessary exposure with an apparatus such as that described is from 3 to 5 minutes; when low powers such as one inch or a half-inch objective is used, all the sub-stage condensing systems are removed, so that the light entering from the polarising Nicol forms a nearly parallel beam; it is also advisable to rotate the Nicols so that their planes of polarisation are horizontal and vertical, in order that the negative and prints shall show at once the direction of extinction in the crystalline fragments. The objects are photographed between crossed Nicols, not only to show the extinction directions, but mainly because the outlines and details of doubly refracting preparations, although nearly invisible in ordinary light, become plainly visible and stand out with great boldness when examined or photographed between crossed Nicols.

* The fact that the degree of impurity of the material seems to affect the speed of interconversion of the $\alpha$ - and $\beta$-moditications has led Dr. Armstrong to suggest that the two forms perhaps have the constitution $\mathrm{CCl}_{3} \cdot \mathrm{COH}, \mathrm{H}_{2} \mathrm{O}$ and $\mathrm{CCl}_{3} \cdot \mathrm{CH}(\mathrm{OH})_{2}$. Compare W. H. Perkin, sen., Trans., 1887, 51, 808. 
The method of obtaining the pictures reproduced in the plates is thus detailed because of its great value as a means of identifying substances. A photomicrograph, taken under definite and stated conditions such as those now described, is highly characteristic in the case of many substances, and, if accompanied by a few lines stating the optical characteristics of the crystalline flakes composing the film, affords a rapid and almost infallible method of judging as to the identity or otherwise of two preparations.

In order, as stated above, to obtain a permanent record of the interconversion of $\alpha$ - and $\beta$-chloral hydrate, sets of photomicrographs were taken of various preparations.

A set of photographs depicting the state of chloral hydrate during a period of six days after solidification is found in numbers $1,2,3$, and 4 of the plate; (p. 464) the magnification is here only 30 diameters. Number 1 consists wholly of the acicular $\beta$-modification, and was taken one hour after solidification; in number 2 , taken two days later, a few diamond-shaped pieces are observable, but the main bulk of the mass consists of the $\beta$-modification. In picture number 3 , taken four days after solidification, the diamond-shaped pieces depicted in number 2 are observed to have grown considerably at the expense of the needles. Photograph number 4, taken six days after solidification, shows that after six days the whole mass consisted of the $\alpha$-variety; other pictures obtained after this stage has been reached show that no further crystallographic change occurs until volatilisation takes place from the sides of the cover-slip.

\section{Crystalline Fiorm of a-Chloral Hydrate.}

Many unsuccessful attempts were made to obtain measurable crystals of chloral hydrate by the spontaneous evaporation of solutions in various solvents; these were usually rendered futile by the property of superfusion possessed by chloral hydrate in a marked degree. Slow sublimation in a Sprengel vacuum, which allows of the formation of well-developed crystals of many substances, such as camphor, which cannot be obtained in large crystals from solution, led to the deposition of broad, thin, rhomboidal plates which could not be detached from the sides of the vessel without destroying them. The crystals ultimately found to give the best goniometrical results were obtained by dissolving carefully dried chloral hydrate in purified chloroform, and leaving half a litre or so of the solution to evaporate spontaneously in a flask with a plug of cotton-wool in the neck; one lot of solution thus left at constant temperature yielded a crop of small, brilliant crystals (Fig. 1) of stout habit which gave good results on measurement. These crystals were about $0.5 \mathrm{~mm}$. long, and 
POPE : A METHOD OF STUDYING POLYMORPHISM, ETC. 459

were not at all hygroscopic under ordinary atmospheric conditions; the following is their crystallographic description.

Crystalline system.-Monosymmetric.

$$
\begin{gathered}
a: b: c=1 \cdot 6188: 1: 1 \cdot 7701 . \\
\beta=68^{\circ} 52^{\prime} .
\end{gathered}
$$

Forms present. $-a\{100\}, c\{001\}, \quad r\{101\}, \quad p\{110\}, \quad q\{011\}, o\{111\}$, and $w\{111\}$.

Fig. 1.

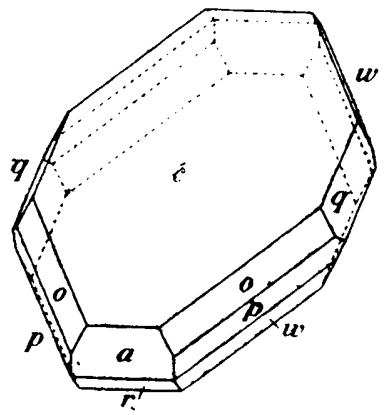

\begin{tabular}{|c|c|c|c|c|}
\hline Angle. & $\begin{array}{c}\text { Number of } \\
\text { observations. }\end{array}$ & Limits. & Mean. & Calculated. \\
\hline $\begin{array}{l}a c=100: 001 \\
c r=001: \overline{1} 01 \\
a r=\overline{1} 00: \overline{1} 01 \\
a 0=100: 111 \\
o q=111: 011 \\
a q=100: 011 \\
q w=011: \overline{1} 11 \\
a w=\overline{1} 00: \overline{1} 11 \\
a p=100: 110 \\
p p=110: \overline{1} 10 \\
c o=001: 111 \\
c p=001: 110 \\
c p=111: 110 \\
p w=110: 11 \overline{1} \\
c 20=00 \overline{1}: 11 \overline{1} \\
c q=001: 01 \overline{1} \\
q q=011: 01 \overline{1} \\
o v=111: \overline{1} 1 \overline{1} \\
o 0=111: 1 \overline{1} 1 \\
r w=\overline{1} 01: \overline{1} 11 \overline{1} \\
w o w=\overline{1} 11: \overline{1} 1 \overline{1}\end{array}$ & $\begin{array}{r}37 \\
18 \\
11 \\
24 \\
39 \\
17 \\
26 \\
20 \\
29 \\
64 \\
59 \\
71 \\
27 \\
17 \\
69 \\
44 \\
21 \\
18 \\
13 \\
16 \\
8\end{array}$ & 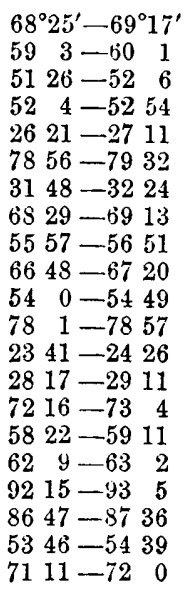 & $\begin{array}{lr}68^{\circ} & 49^{\prime} \\
59 & 27 \\
51 & 41 \\
52 & 23 \\
26 & 49 \\
79 & 17 \\
32 & 6 \\
68 & 44 \\
56 & 28 \\
67 & 2 \\
54 & 23 \\
78 & 31 \\
24 & 8 \\
28 & 47 \\
72 & 40 \\
58 & 41 \\
62 & 37 \\
92 & 41 \\
87 & 19 \\
54 & 12 \\
71 & 36\end{array}$ & $\begin{array}{ll}68^{\circ} 52^{\prime} & 59 \\
51 & 18 \\
51 & 50 \\
52 & 31 \\
26 & 43 \\
79 & 14 \\
31 & 54 \\
68 & 52 \\
5629 \\
- \\
54 & 18 \\
- \\
24 & 13 \\
28 & 49 \\
- \\
5848 \\
62 & 24 \\
92 & 35 \\
87 & 25 \\
54 & 18 \\
71 & 24\end{array}$ \\
\hline
\end{tabular}

The following angular measurements were obtained.

The form $c\{001\}$ is dominant, and gives very good reflections on the goniometer; the faces of all the other forms are very small and vary in size, but give very good results on measurement. The crystals 
possess a very perfect cleavage parallel to $c\{001\}$, and on examining the crystals conoscopically between crossed Nicols through this form, one optic axis is seen to emerge in the plane of symmetry; the optic axial plane is thus the plane of symmetry, and the obtuse bisectrix, which shows positive double refraction, emerges through $c(001)$. The optic axial angle is fairly small, the double refraction negative, and the dispersion slight.

Measurements of a few angles on chloral hydrate crystals have been published by Groth (Ber., 1872, 5, 675) and des Cloizeaux (Bul. soc. min. franc., 1885, 8, 123) ; Dufet (Bul. soc. min. fronc., $1891,14,206)$ has given more complete measurements, and his values agree very well with those now published, but he did not observe the occurrence of the forms $r\{101\}$ and $q\{011\}$ for which I now give measurements. The axial values arrived at by Dufet and by me are,

$$
\begin{aligned}
& \text { Dufet........ } a: b: c=1 \cdot 61776: 1: 1 \cdot 77047 . \quad \beta=68^{\circ} 49 . \\
& \text { Pope ........ } a: b: c=1 \cdot 6188: 1: 1 \cdot 7701 . \quad \beta=68^{\circ} 52^{\prime} .
\end{aligned}
$$

\section{Localisution of Hygroscopic Power.}

One batch of chloral hydrate crystals from a commercial source allowed of some interesting observations respecting hygroscopic power. On exposing a well-developed crystal to the air for a short time, it was observed that, although the faces of the form $c\{001\}$ remained dry and bright for half an hour or more, those of the other forms, $a\{100\}, p\{110\}, q\{011\}, o\{111\}$, and $\left.w_{\{11} 1\right\}$, rapidly absorbed moisture and in a few minutes were completely covered with a layer of liquid. No observations seem to have been previously made respecting the variation of hygroseopicity with the direction in crystalline substances, so that the observation that the form $c\{001\}$ absorbs moisture from the air less rapidly than the other forms is the only one on which any views as to the localisation of hygroscopic power can be based, but the observations here recorded are suggestive, and it is obviously of interest to further study the question.

\section{Bromal Hydrate.}

Bruner (Compt. rend., 1895, 120, 914), on studying the thermochemical behaviour of bromal hydrate, found that, after fusing and resolidifying, its heat of dissolution is greater than that of bromal hydrate which has not been fused. On dissolution in potash, bromal hydrate which has not been fused evolves +12.08 cals., but one hour after fusion and resolidification it evolves $+16 \cdot 12$ cals. It was, therefore, expected that bromal hydrate would be obtainable in two 
modifications analogous to those of chloral hydrate, that is to say, that chloral and bromal hydrates would be isodimorphous ; curiously enough, however, this is not the case.

A carefully purified specimen of bromal hydrate was dried in a vacuum over calcium chloride, and found to melt quite sharply at $53.5^{\circ}$, and to give, on analysis, numbers corresponding with the compo. sition $\mathrm{CBr}_{3} \cdot \mathrm{CH}(\mathrm{OH})_{2}$.

$0 \cdot 1941$ gave $0 \cdot 3684 \mathrm{AgBr} . \quad \mathrm{Br}=80 \cdot 10$.

$\mathrm{CBr}_{3} \cdot \mathrm{CH}(\mathrm{OH})_{2}$ requires $\mathrm{Br}=79.98$ per cent.

After fusion on a microscope slide in the manner described above, it readily solidifies from centres to a confusedly radiate mass of much higher double refraction than the $\beta$-variety of chloral hydrate. The individual crystals scarcely ever extinguish parallel to their directions of growth, and are usually smaller than those of chloral hydrate. In the larger pieces, the acnte bisectrix of a biaxial crystal generally emerges obliquely from the face of the plate; the optic axial angle is large, and the crystals are probably monosymmetric. Series of photographs of the film taken at intervals during a period of several weeks indicate that no change of crystalline form occurs, the only slight changes in the character of the mass being such as are attributable to gradual volatilisation. No evidence of dimorphism in bromal hydrate has thus been obtained.

Bromal hydrate is less soluble than the corresponding chloral com pound, and can be obtained in masses of interlaced needles, by cooling the hot solution. The concentrated cold solution, on spontaneous evaporation in a vacuum over calcium chloride, deposits very beautiful, transparent crystals; these are long, hard, brittle prisms possessing ligh lustre, and belong to the monosymmetric system. After withdrawal from the solution, the crystals are best dried for crystallographic examination with a soft linen cloth; this, it may be mentioned, is perhaps the best way of removing mother liquor from crystals destined for measurement. The crystals may readily be obtained of $8-10 \mathrm{~cm}$. in length and $2-3 \mathrm{~cm}$. in breadth. Carius determinations made on this material show it to have the composition $\mathrm{CBr}_{3} \cdot \mathrm{CH}(\mathrm{OH})_{2}+\mathrm{H}_{2} \mathrm{O}$.

$0 \cdot 2091$ gave 0.3699 $\mathrm{AgBr} . \quad \mathrm{Br}=75 \cdot 27$.

$0 \cdot 1810,0 \cdot 3204 \mathrm{AgBr} . \quad \mathrm{Br}=75 \cdot 30$. $\mathrm{CBr}_{3} \cdot \mathrm{CH}(\mathrm{OH})_{2}+\mathrm{H}_{2} \mathrm{O}$ requires $\mathrm{Br}=75 \cdot 21$ per cent.

Crystalline system.-Monosymmetric.

$$
\begin{aligned}
a: b: c & =1 \cdot 7861: 1: 1 \cdot 3048 . \\
\beta & =58^{\circ} 28^{\prime} .
\end{aligned}
$$

Forms present. $-a\{100\}, c\{001\}, r\{\overline{1} 01\}$, and $q\{011\}$.

VOL. LXXV. 
Fit: 2.

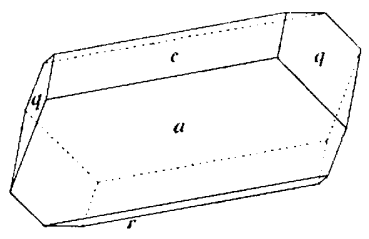

The following angular measurements were obtained.

\begin{tabular}{|c|c|c|c|c|}
\hline Angle. & $\begin{array}{l}\text { Number of } \\
\text { observations. }\end{array}$ & I.imits. & Mcan. & Calculated. \\
\hline $\begin{aligned} a c & =100: 001 \\
c i & =001: \overline{1} 01 \\
a r & =100: 10 \overline{1} \\
a q & =100: 011 \\
a q & =\overline{1} 00: 011 \\
c q & =001: 011 \\
q q & =011: 011 \\
r q & =\overline{1} 01: 011 \\
r q & =10 \overline{1}: 011\end{aligned}$ & $\begin{array}{r}49 \\
51 \\
47 \\
74 \\
64 \\
48 \\
22 \\
6 \\
9\end{array}$ & $\begin{array}{r}58^{\circ} 11^{\prime}-58^{\circ} 46^{\prime} \\
4458-4532 \\
761-7636 \\
713-7149 \\
10820-1090 \\
527-532 \\
7413-7516 \\
649-6514 \\
11438-11547\end{array}$ & $\begin{array}{rl}58^{\circ} 28^{\prime} \\
45 & 13 \\
76 & 19 \\
71 & 27 \\
108 & 33 \\
52 & 33 \\
74 & 19 \\
64 & 41 \\
115 & 19\end{array}$ & $\begin{array}{r}\overline{-} \\
769^{\prime} \\
\overline{-} \\
10833 \\
5233 \\
7156 \\
6438 \\
11523\end{array}$ \\
\hline
\end{tabular}

The pinacoid forms $a\{100\}$ and $\left.c_{\{} 001\right\}$ are usually dominant, and give very perfect reflections on measurement; the prism $r\{101\}$ is always small, but gives good results. The dome $q\{011\}$ is very brilliant, and gives trustworthy measuremonts (Fig. 2).

The optic axial plane is perpendicular to the plane of symmetry, and the acute bisectrix is observed through the face $a(100)$, emerging in the angle $\operatorname{ar}(100: 10 \overline{\mathrm{l}})$; the optic axial angle is moderately large, the dispersion slight, and the double refraction negative in sign.

After a few hours exposure to the air, the crystals become opaque, but retain their shape and to a certain extent their lustre, becoming at the same time rather more friable; on microscopic examination, the opaque crystals are seen to be no longer single crystalline individuals, but to be covered with an interlaced mass of tiny needles and to show aggregate polarisation. The fresh, transparent crystals begin to melt at $46^{\circ}$, but do not completely liquefy until $50-52^{\circ}$; after solidification, the substance melts for the second time at $50^{\circ}$ but still not sharply, so that its behaviour is altogether that of a mixture. After exposing the powdered substance over calcium chloride in a vacuum for a few days, it melts both for the first and second time at $53.5^{\circ}$; it is therefore evident that the change is due, not to dimorphism, but to loss of water of crystallisation.

No explanation can thus be found, in polymorphism, of Bruner's 
statement that bromal hydrate exhibits anomalous thermal behaviour just like chloral hydrate; Bruner, however, does not state whether any precaution was taken to ensure that the bromal hydrate used had the composition $\mathrm{CBr}_{3} \cdot \mathrm{CH}(\mathrm{OH})_{2}$ and was quite free from the material containing water of crystallisation.

The statement has crept into the literature that bromal hydrate is not isomorphous with chloral hydrate. This has anisen from Lüwig's statement (Ann. chim. phys., 1832, [ii], 26, 288) that bromal hydrate crystallises in prisms having the form of copper sulphate; this remark refers to the hydrated material $\mathrm{CBr}_{3} \cdot \mathrm{CH}(\mathrm{OH})_{2}+\mathrm{H}_{2} \mathrm{O}$, which naturally could not be isomorphous with a substance of the composition $\mathrm{CCl}_{3} \cdot \mathrm{CH}(\mathrm{OH})_{2}$. Attempts were made to obtain crystals of the composition $\mathrm{CBr}_{3} \cdot \mathrm{CH}(\mathrm{OH})_{2}$ in a form suitable for measurement, by crystallising the dry material from dry chloroform or carbon bisulphide; under these circumstances, large, rhomb-shaped, monosymmetric plates, which melted at $53 \cdot 5^{\circ}$ and closely resembled the crystals of chloral hydrate described above, were obtained. The only form sufficiently well developed for examination is $c\{001\}$; there is perfect cleavage parallel to this form, and an optic axis emerges nearly normally through it, the optic axial plane being the plane of syrnmetry. It is thus evident that chloral hydrate is isomorphous with bromal hydrate.

\section{Menthol.}

In order to ascertain whether the variations in the heats of dissolution of chloral hydrate and bromal hydrate are due to incomplete solidification, Bruner (loc. cit.) examined the behaviour of mentbol and thymol, substances which he describes as of a somewhat pasty nature, but found that the latent heats of fusion of these are definite quantities which do not vary with the period elapsing since solidification.

Many attempts were made to cultivate measurable crystals of menthol by crystallisation from various solvents, but these were uniformly unsuccessful, owing to the facility with which the substance remains superfused after evaporation of the solvent.

Fused menthol solidifies easily from centres in very long, narrow needles; these are doubly refracting, but so small that no information as to crystalline form can be obtained by their microscopic examination. As cooling proceeds, a sudden alteration in crystalline structure occurs, and the whole material changes with great rapidity into a confused mass of minute, doubly refracting needles, showing aggregate polarisation, but which are so very small that all attempts to determine their crystallograpinic properties have been unsuccessful. The change in 
crystalline form sets in some five minutes or so after the material solidifies; this allows just sufficient time to photograph the first crystalline modification before its sudden conversion into the second modification takes place. Photographs 5 and 6 were obtained in this manner, and represent the same spot in the film before and after the crystallographic change.

Although menthol, like chloral hydrate, is dimorphous, yet Bruner found no variable thermal constarts; the reason of this is obviously that the change of the one form of menthol into the other occurs so readily at ordinary temperatures that Bruner was never able to determine the hent of combustion or of dissolution of the unstable modification.

\section{Thymol.}

This substance crystallises on spontaneous evaporation of its solution in acetic acid, ethylic acetate, or acetone, in very beautiful, lustrons, transparent, colourless plates; the crystals belong to the rhombohedral system, and exhibit a perfect cleavage parallel to $r\{100\}$. One face of $r\{100\}$ is usually dominant, and this form is always the largest present; the form $s\{110\}$ is smaller, but yet well developed. The basal pinacoid $c\{111\}$ is small, and the prism $p\{\overline{1} 10\}$ is not very frequently observed (Fig. 3). All the forms present on the crystals give excellent results on measurement. The double refraction is positive and weak.

A few angles on crystals of thymol have also been determined by Groth (Ann. Phys. Chem., 1868, 135, 655), and by Miller (Annalen, $1856,98,310)$, but no complete series of measurements has been yet published, and the occur rence of the form $p\{110\}$ has not previously been observed.

Crystalline system.-Hexagonal, Rhombohedral Hemihedrism.

$$
\begin{aligned}
& a: c=1: 1.5679 . \quad a=79^{\circ} 51^{\prime} 40^{\prime \prime} \\
& \text { Groth ... } \quad a: c=1: 1 \cdot 5685 . \quad \alpha=79^{\circ} 52^{\prime} 30^{\prime \prime}
\end{aligned}
$$

FIG. 3.

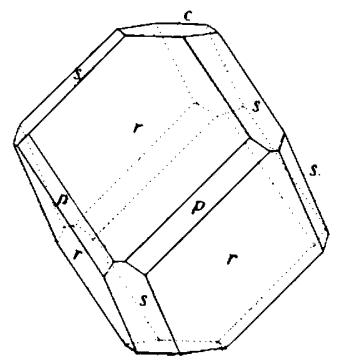


ON POLYMORPHISM, BY W. J. POPE.

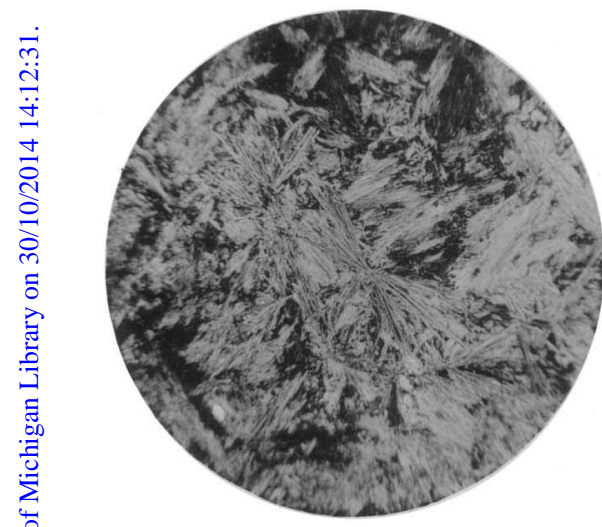

No. $1 \times 30$.

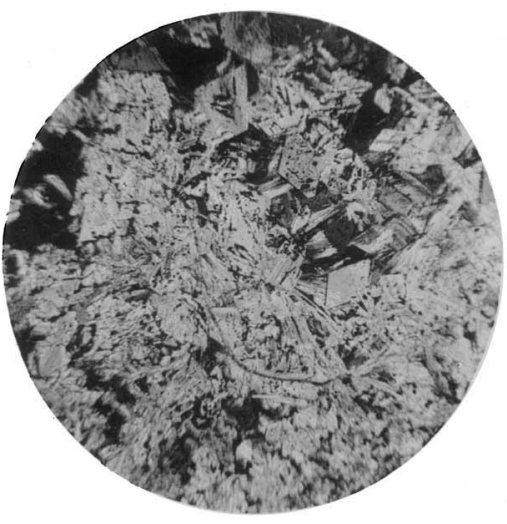

No. $3 \times 30$.

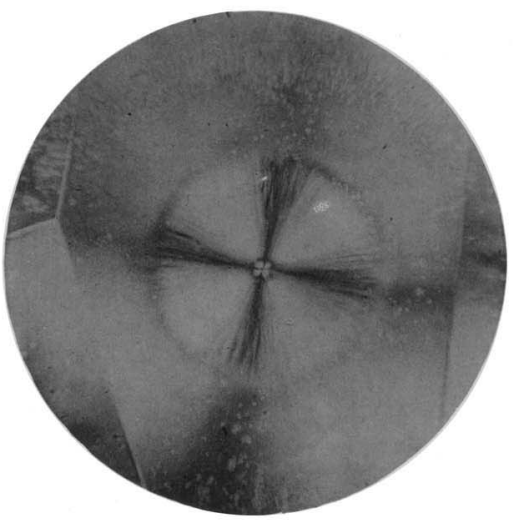

No. $5 \times 400$.

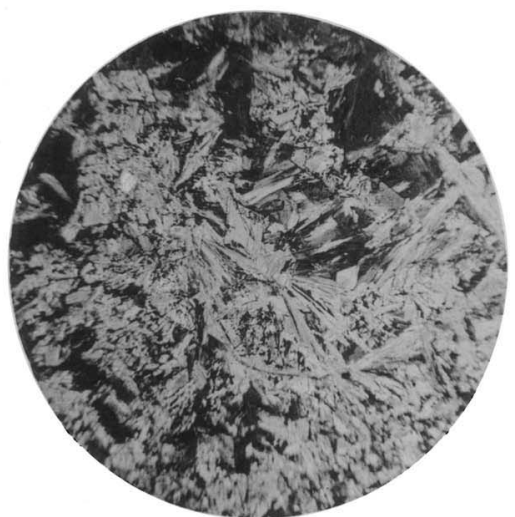

No, $2 \times 30$.

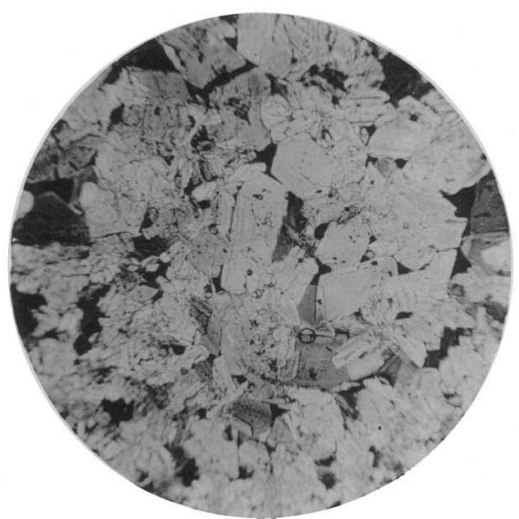

No. $4 \times 30$.

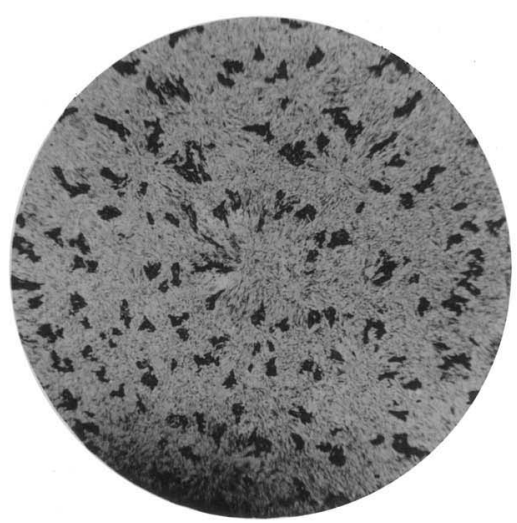

No. $6 \times 400$. 
CHARACTERISATION OF RACEMIC COMPOUNDS.

Forms observed.

$\begin{array}{llllll}c & \ldots \ldots \ldots \ldots & \{111\} & \ldots \ldots \ldots \ldots & \{0001\} \\ \boldsymbol{r} & \ldots \ldots \ldots \ldots & \{100\} & \ldots \ldots \ldots \ldots & \{10 \overline{1} 1\} \\ \boldsymbol{s} & \ldots \ldots \ldots \ldots & \{110\} & \ldots \ldots \ldots \ldots & \{01 \overline{1} 2\} \\ p & \ldots \ldots \ldots \ldots & \{\overline{1} 10\} & \ldots \ldots \ldots \ldots & \{\overline{2} 110\}\end{array}$

The following angular measurements were obtained.

\begin{tabular}{|c|c|c|c|c|c|c|}
\hline Angle. & $\begin{array}{l}\text { Number of } \\
\text { measure- } \\
\text { ments. }\end{array}$ & Limits. & Mean. & $\begin{array}{l}\text { Calcu- } \\
\text { lated. }\end{array}$ & Miller. & Groth. \\
\hline $\begin{array}{l}c r=111: 100 \\
c s=111: 011 \\
r s=100: 011 \\
r s=\overline{1} 00: 011 \\
p r=10 \overline{1}: 100 \\
r s=100: 101 \\
r r=100: 010 \\
s s=101: 011 \\
p p=10 \overline{1}: 01 \overline{1} \\
r r=100: 0 \overline{1} 0 \\
p s=\overline{1} 10: 011\end{array}$ & $\begin{array}{r}24 \\
15 \\
17 \\
21 \\
20 \\
18 \\
12 \\
18 \\
10 \\
9 \\
14\end{array}$ & 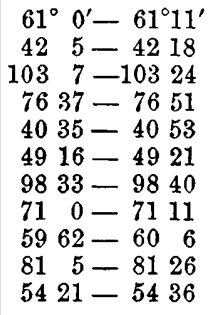 & $\begin{array}{rl}61^{\circ} & 6^{\prime} \\
42 & 10 \\
103 & 16 \\
76 & 43 \\
40 & 43 \\
49 & 18 \\
98 & 36 \\
71 & 6 \\
60 & 0 \\
81 & 23 \\
54 & 28\end{array}$ & \begin{tabular}{|cc}
\multicolumn{4}{c}{$\overline{42^{\circ}} 10^{\prime}$} \\
103 & 16 \\
76 & 44 \\
40 & 42 \\
49 & 18 \\
98 & $36 \cdot 5$ \\
71 & $5 \cdot 5$ \\
60 & 0 \\
81 & $23 \cdot 5$ \\
54 & 27
\end{tabular} & $\begin{array}{l}61^{\circ} 9^{\prime} \\
4215 \\
\ldots \\
\ldots \\
4039 \\
4919 \\
9841 \\
\ldots \\
\ldots \\
\ldots \\
\ldots\end{array}$ & $\begin{array}{c}61^{\circ} 18^{\prime} \\
\ldots \\
\ldots \\
\ldots \\
\ldots \\
4915 \\
9836 \\
\ldots \\
\ldots \\
\ldots \\
\ldots\end{array}$ \\
\hline
\end{tabular}

After melting on a microscope slide, the substance crystallises sluggishly, yielding a film which is full of cracks, and consists of large, individual flakes; these plates lie nearly parallel to the optic axis or perpendicular to $c\{111\}$, and, therefore, show negative double refraction. An optic axis is never seen emerging in the field; and the substance does not change in crystalline form if kept, photographs taken immediately after solidification being identical in appearance with pictures taken a month later.

Chemical Department,

City and Guilds of London Institute,

Central Technical College,

SOUTH Kensington. 